\title{
Tandem configuration of differential mobility and centrifugal particle mass analysers for investigating aerosol hygroscopic properties
}

\author{
Sergey S. Vlasenko ${ }^{1}$, Hang Su${ }^{2}$, Ulrich Pöschl ${ }^{2}$, Meinrat O. Andreae ${ }^{2,3}$, and Eugene F. Mikhailov ${ }^{1,2}$ \\ ${ }^{1}$ Department of Atmospheric Physics, Saint-Petersburg University, St. Petersburg State University, \\ SPbSU, SPbU, 7/9 Universitetskaya nab., St. Petersburg, 199034, Russia \\ ${ }^{2}$ Biogeochemistry and Multiphase Chemistry Departments, Max Planck Institute for Chemistry, \\ P.O. Box 3060, 55020 Mainz, Germany \\ ${ }^{3}$ Scripps Institution of Oceanography, University of California San Diego, La Jolla, CA 92093, USA
}

Correspondence to: Eugene F. Mikhailov (eugene.mikhailov@ @pbu.ru)

Received: 22 July 2016 - Discussion started: 23 September 2016

Revised: 2 February 2017 - Accepted: 3 March 2017 - Published: 30 March 2017

\begin{abstract}
A tandem arrangement of Differential Mobility Analyser and Humidified Centrifugal Particle Mass Analyser (DMA-HCPMA) was developed to measure the deliquescence and efflorescence thresholds and the water uptake of submicron particles over the relative humidity $(\mathrm{RH})$ range from 10 to $95 \%$. The hygroscopic growth curves obtained for ammonium sulfate and sodium chloride test aerosols are consistent with thermodynamic model predictions and literature data. The DMA-HCPMA system was applied to measure the hygroscopic properties of urban aerosol particles, and the kappa mass interaction model (KIM) was used to characterize and parameterize the concentration-dependent water uptake observed in the 50-95\% RH range. For DMAselected $160 \mathrm{~nm}$ dry particles (modal mass of $3.5 \mathrm{fg}$ ), we obtained a volume-based hygroscopicity parameter, $\kappa_{v} \approx 0.2$, which is consistent with literature data for freshly emitted urban aerosols.

Overall, our results show that the DMA-HCPMA system can be used to measure size-resolved mass growth factors of atmospheric aerosol particles upon hydration and dehydration up to $95 \% \mathrm{RH}$. Direct measurements of particle mass avoid the typical complications associated with the commonly used mobility-diameter-based HTDMA technique (mainly due to poorly defined or unknown morphology and density).
\end{abstract}

\section{Introduction}

The interaction of atmospheric aerosol particles with water vapour results in size changes that strongly affect the optical properties of the aerosol particles and consequently their direct radiative effect on the Earth's energy budget (Waggoner et al., 1981; Rastak et al., 2014, and references therein). Furthermore, hydrophilic aerosol particles are able to act as cloud condensation nuclei, thereby modifying the radiative properties and lifetime of clouds (indirect aerosol effects) (Twomey, 1977; Haywood and Boucher, 2000). Additionally, hygroscopicity is an important factor in the chemical reactivity of aerosols (Shiraiwa et al., 2013). Therefore, the hygroscopic properties of aerosol particles have been of interest throughout the whole history of aerosol study, with respect to both the direct description of their hygroscopic growth and the influence on their optical parameters (Orr et al., 1958; Hänel, 1976; Rader and McMurry, 1986; Berg et al., 1998; Cheng et al., 2008; Fierz-Schmidhauser et al., 2010a, b; Zieger et al., 2013).

Humidified Tandem Differential Mobility Analysers (HTDMAs) are the most commonly used instrument to study the hygroscopic behaviour of size-selected aerosol particles (McMurry and Stolzenburg, 1989; Brechtel and Kreidenweis, 2000a; Gysel et al., 2002; Mikhailov et al., 2004; Eichler et al., 2008; Swietlicki et al., 2008). The first DMA selects particles of a specific size from the previously dried polydisperse aerosol. While the selected particles are not truly 
monodisperse due to multiple charging effects, non-ideality of the DMA transfer function, etc., the width of the output size distribution is small enough to consider the aerosol as quasi-monodisperse. Then this aerosol is humidified to a set $\mathrm{RH}$. The number size distribution of the humidified sample is then measured by a second DMA operated at the same RH as the humidified sample. The HTDMA method is used for both laboratory and field measurements, and typically covers the particle mobility diameter in the range of 6-300 nm. However, this instrument classifies particles according to their electrical mobility, and therefore the water uptake is calculated indirectly, with an uncertainty introduced by lack of knowledge about particle shape and density (DeCarlo et al., 2004; Gysel et al., 2004; Mikhailov et al., 2004).

A number of alternative detectors have been employed to replace the second DMA to probe the hygroscopic properties of the size-selected atmospheric aerosol. Several studies used an optical particle counter (OPC) (Covert et al., 1990; Hering and McMurry, 1991; Brand et al., 1992; Kreisberg et al., 2001). Sorooshian et al. (2008) proposed a differential aerosol sizing and hygroscopicity spectrometer probe (DASH-SP), which employs four OPCs to measure the hygroscopic growth at three RHs simultaneously and thereby reduces measurement time. Massling et al. (2007) applied a Hygroscopicity Differential Mobility AnalyserAerodynamic Particle Sizer system (H-DMA-APS) to measure the hygroscopic properties of aerosol particles at or near $1 \mu \mathrm{m}$ dry diameter during ACE-Asia. Some other methods deal with polydisperse aerosol particles. Snider and Peters (2008) and Hegg et al. (2007) obtained growth factors by comparing OPC size distributions measured at different RHs. Many researchers employed humidity controlled nephelometers and estimated growth factors from the variation of aerosol light scattering coefficients with changing RH (Magi and Hobbs, 2003; Kim et al., 2006; Fierz-Schmidhauser et al., 2010a, b). All of these methods rely on certain assumptions (particle morphology, density, refractive index, etc.) to convert optical or mobility growth factor measurements into a mass-based scale.

However, mass-based measuring techniques are more appropriate to describe the water uptake of aerosols in conjunction with thermodynamic or parametric models (Mikhailov et al., 2013). The single particle levitation technique is commonly used for the direct measurement of the water vapour uptake/release by particles due to RH variations (Tang and Munkelwitz, 1993, 1994; Peng and Chan, 2001). This technique enables high-precision measurements of the mass growth factor in hydration and dehydration mode, but it is applicable only to supermicron (typically $5-25 \mu \mathrm{m}$ ) particles and can be used only in laboratory conditions. The other mass-based techniques employ aerosol sampled on filters (Lee and Hsu, 1998; Mikhailov et al., 2011). This approach is suitable for measurements of ambient aerosol, but only in offline mode, and therefore, the loaded filters require careful handling to avoid possible particle mass loss between sampling and measuring.

The most reliable online technique for measuring submicron particle mass is based on the Ehara aerosol particle mass analyser (APM; Ehara et al., 1996) in combination with a DMA. The early studies based on this technique were used to determine the density and shape factor of size-selected test particles and atmospheric aerosols (McMurry et al., 2002; Geller et al., 2006). Kondo et al. (2006) mounted a heater upstream of the DMA and used the DMA+APM technique to measure the relationship between mass and size of nonvolatile particles in ambient air. In the more recent publications, the DMA+APM technique was used to follow the aging of soot particles and the change of effective density due to condensation of organic (oleic acid and anthracene) (Slowic et al., 2007) and inorganic (sulfuric acid and water) species (Pagels et al., 2009; Johnson et al., 2015). In the latter work, the combination of DMA and CDMA was used to measure the mass growth factor of tobacco smoke particles as function of increasing RH. This technique is quite similar to ours.

We present here an application of the DMA-HCPMA tandem configuration to study the hygroscopic growth of aerosol particles. A hygroscopicity centrifugal particle mass analyser (HCPMA) was employed for direct measurements of particle mass increase/decrease due to water uptake/release. The concept has been briefly introduced in Vlasenko and Mikhailov (2013). In this paper, we present a detailed description of the experimental procedure and results obtained for both laboratory-generated particles and ambient atmospheric aerosols. Our work is mainly focused on the applicability of the tandem DMA-HCPMA set-up for investigating the hydration/dehydration of aerosol particles, including deliquescence/efflorescence phase transitions.

\section{Experiment}

A sketch of the HCPMA system is shown in Fig. 1. Aerosols were generated by nebulization of aqueous solutions of the investigated pure substances in deionized water $(18.2 \mathrm{M} \Omega \cdot \mathrm{cm}$, Millipore - Milli-Q plus 185$)$ with a solute mass fraction $0.01 \%$, using a constant output atomizer (TSI, model 3075). The following reference substances were used to prepare test aerosols for the proposed method: ammonium sulfate $\left(\left(\mathrm{NH}_{4}\right)_{2} \mathrm{SO}_{4}\right.$, Fluka, $\left.>99.5 \%\right)$ and sodium chloride $(\mathrm{NaCl}$, Merck, $>99.5 \%$,). The solution droplets were dried using a silica gel diffusion dryer (SDD) with aerosol residence time $\sim 10 \mathrm{~s}$; the residual relative humidity was $<10 \%$ throughout all experiments. The dry polydisperse aerosol was passed through a neutralizer (NL) (X-ray, Model TSI 3087), and a quasi-monodisperse aerosol with the desired initial dry particle mobility diameter $\left(D_{\mathrm{b}}\right)$ was selected by the differential mobility analyser (DMA, Model TSI 3081). The resulting quasi-monodisperse particles were 


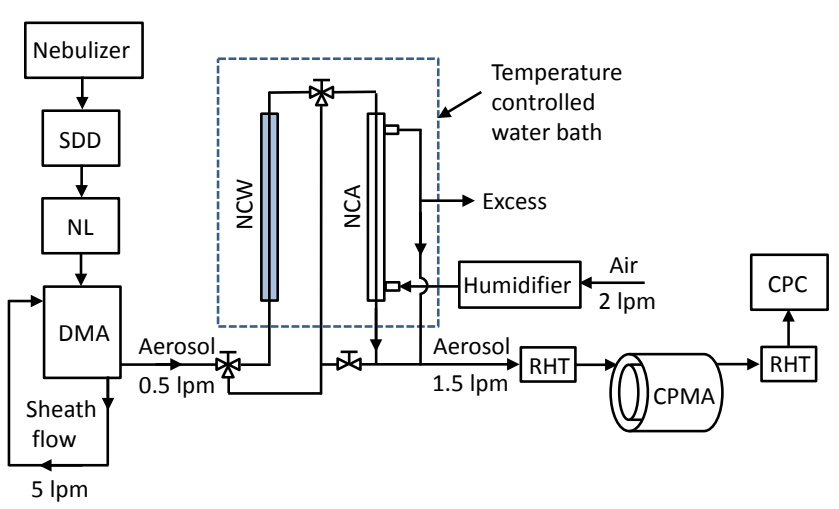

Figure 1. Experimental set-up of the hygroscopicity centrifugal particle mass analyser (HCPMA) system: SDD (silica gel diffusion dryer), NL (aerosol neutralizer), DMA (differential mobility analyser), NCW (Nafion conditioner with water), NCA (Nafion conditioner with air), RHT (relative humidity and temperature sensor), CPMA (centrifugal particle mass analyser), CPC (condensation particle counter).

then flowed at $0.5 \mathrm{~L} \mathrm{~min}^{-1}$ through a series of one or two single-tube Nafion humidity exchangers.

In hydration mode, the outer tube of the humidity exchanger ( $2.4 \mathrm{~m}$ long) was supplied with humidified air at controlled RH. The RH was increased stepwise from 15 to $95 \%$ by the mixing of dry air with an airflow saturated with water vapour, varying the ratio of humidified to dry air to produce a total flow of $2 \mathrm{~L} \mathrm{~min}^{-1}$. Water-saturated air was produced by bubbling clean- and dry-filtered air (TSI 3074B) through water heated to $36^{\circ} \mathrm{C}$ (Mikhailov et al., 2004). The hydration mode provides information about deliquescence phase transitions of dry particles and the hygroscopic growth of deliquesced particles (aqueous solution droplets) as a function of relative humidity. The aerosol residence time in the conditioner and subsequent lines leading to the CPMA is $\sim 10 \mathrm{~s}$.

In dehydration mode, a series of two Nafion humidity exchangers was used for aerosol RH conditioning. The outer tube of the first one ( $1.2 \mathrm{~m}$ long) was filled with water, which caused the particles to deliquesce and form aqueous droplets. The outer tube of the second one ( $2.4 \mathrm{~m}$ long) was supplied with air at controlled RH that decreased stepwise from 95 to $15 \% \mathrm{RH}$. The dehydration mode allows for studying the hysteresis effect and efflorescence of aerosol particles.

The relative humidity $(\mathrm{RH})$ and the temperature $(T)$ of the aerosol flow at the inlet and outlet of the CPMA were measured with capacitive humidity sensors (accuracy $\pm 2 \% \mathrm{RH}$ ) and temperature sensors (accuracy $\pm 0.1 \mathrm{~K}$ ) (ALMEMO 2390, Ahlborn FH A646-E1C).

The heart of the apparatus is a centrifugal particle mass analyser (CPMA, Cambustion Ltd) designed for classifying aerosol particles according to their mass-to-charge ratio. The analyser consists of two rapidly spinning coaxial cylindrical electrodes. The initially charged aerosol particles pass through the annular interelectrode space, where they experience centrifugal and electrostatic forces acting in opposite directions (Ehara et al., 1996). Depending on the rotation speed and voltage applied, these forces are balanced for aerosol particles with a certain mass-to-charge ratio. These particles move through the analyser without precipitating on the electrodes. The other particles are forced either to the inner or to the outer electrode and adhere to their surfaces. Thus, a CPMA selects particles with a mass $\left(m^{*}\right)$, provided that the charge on the particles is the same and known (Olfert et al., 2006).

$m^{*}=\frac{z e V}{\omega_{\mathrm{c}}^{2} r_{\mathrm{c}}^{2} \ln \left(\frac{r_{1}}{r_{2}}\right)}$,

where $V$ is the voltage between inner and outer cylinders with radii $r_{1}$ and $r_{2}, z$ is the number of elementary charges $e$ on the particles, $r_{\mathrm{c}}=\left(r_{1}+r_{2}\right) / 2$ is the centre radius, and $\omega_{\mathrm{c}}$ is the angular velocity at $r_{\mathrm{c}}$. To improve the transfer function of the classifier, the outer electrode rotates slightly faster than the inner one, producing a stable system of forces (Olfert and Collings, 2005). The particle mass analyser was operated in the step-by-step scanning mode, where rotation speed and applied voltage are varied in a discrete way to scan the desirable particle mass range. The CMPA, in conjunction with the condensation particle counter (CPC) (TSI model 3787), measured the particle-mass-based spectrum as a function of the applied RH history. In the scanning mode, the detector (CPC) registers at each step the total concentration, $\Delta N$, of particles passing through the CPMA. This concentration mainly depends on the width and the amplitude of the CPMA transfer function, which is essentially triangular in case of neutral stability. The mass setpoint defined by Eq. (1) corresponds to the centre of the transfer function. The width $\Delta m$ of the function at the half-maximum level determines the mass resolution of the CPMA. In scanning mode, the resolution parameter of the CPMA, $R=m^{*} / \Delta m$ is automatically maintained at the preset value. Therefore, the CPMA in fact provides the averaged mass spectral density $-\Delta N / \Delta m$ or in $\operatorname{logarithmic~scale~} \Delta N / \Delta \log (m)=\Delta N / \log \left(1+1 / R_{m}\right)$. The resolution parameter of the CPMA depends on voltage, rotational rate, airflow and indirectly on the desired mass range. Its selection is a compromise between the opposing conditions. For example, high resolution requires rapid electrode rotation and high voltage, which increases heat production and risk of discharge inside the CPMA. In the present work, we used the default $R=5$, which corresponds to geometric standard deviations of 1.08 and 1.03 in the mass and size domains respectively. The main experimental challenge was caused by heat generation inside the CPMA due to the friction generated by the rotating cylinders and the heat produced by the electric motor. This led to a gradual warming of the air passing through the CPMA and a corresponding RH decrease. To minimize the difference in RH in the CPMA analyser, the Nafion humidity exchangers and connecting 
tubes were immersed into a water bath circulator with controlled temperature to provide a gradual heating of the humidified aerosol flow in agreement with the CPMA internal temperature growth. Usually the CPMA temperature stabilized at $4-6^{\circ}$ above room temperature after $3-4 \mathrm{~h}$ of continuous operation, depending on average rotation speed. Additionally, a humidified aerosol flow $\left(0.5 \mathrm{~L} \mathrm{~min}^{-1}\right)$ was mixed in downstream of the Nafion conditioner with air (NCA) flow $\left(1 \mathrm{~L} \mathrm{~min}^{-1}\right.$ ) (Fig. 1). Using these operation modes, it was possible to ensure an agreement between the RHs at the inlet and outlet of the CPMA within $2 \% \mathrm{RH}$.

The dry aerosol particle mass was determined at the beginning of every measurement cycle. For this purpose, the DMA-selected particles were introduced directly into the CPMA, bypassing the humidity exchangers. Then, the aerosol flow was redirected through the humidifier system with preset $\mathrm{RH}$, and, after stabilization of the aerosol RH, a spectrum of particle concentration versus mass of the humidified aerosol was measured by the CPMA. The total CPMA scanning time over a measurement cycle depends on the desired mass range and resolution. Due to mass distribution broadening with increasing $\mathrm{RH}$, more scanning steps are needed to provide the same CPMA mass spectra resolution over the entire RH range. In this study, the CPMA scanning time varied within $10-20 \mathrm{~min}$. The lower value refers to the dry aerosol conditions.

Figure 2 is an example of the mass-based distribution of ammonium sulfate particles measured at 10,77 , and $85 \%$ RH. It shows that upon hydration the initial narrow averaged mass spectral density of the dry aerosol particles (modal $m_{\mathrm{d}}=0.18 \mathrm{fg}$ ) became broader, and the maximum of the distribution shifted to a larger mass range.

The hygroscopic mass growth factor is defined as the relative particle mass increase due to water uptake:

$G_{m}=\frac{m_{\mathrm{w}}+m_{\mathrm{d}}}{m_{\mathrm{d}}}$,

where $m_{\mathrm{d}}$ is the mass of the dry particles and $m_{\mathrm{W}}$ is the mass of water in the wet particles. To calculate the mass growth factor from the CPMA data, we used the expression

$G_{m}(\mathrm{RH})=\frac{m_{\mathrm{mod}}(\mathrm{RH})}{m_{\bmod }(\mathrm{RH}<15 \%)}$,

where $m_{\text {mod }}(\mathrm{RH})$ is the modal mass value of the averaged mass spectral density measured at given $\mathrm{RH}$, as specified in Fig. 2.

Obviously, the concept of the described method is quite similar to the widely used HTDMA technique. This approach deals only with modal values of relatively narrow distributions, which makes it less sensitive to the effects of such instrumental factors as transport losses, detection efficiency and multiple charging. Following Rawat et al. (2016) and Stolzenberg and McMurry (2008), the registered particle concentration can be linked to the mass-based distribution

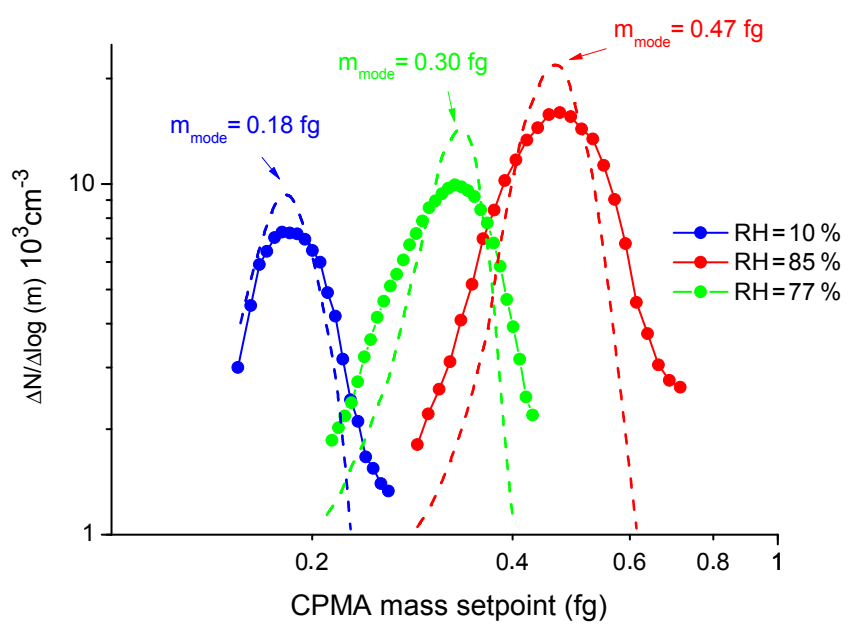

Figure 2. HCPMA measured particle number mass distribution of ammonium sulfate at different RH with initial dry particle modal mass $m_{\mathrm{d}}=0.18 \mathrm{fg}$. The indicated $m_{\text {mode }}$ is the modal value of the particle mass distribution used for the mass growth factor $\left(G_{m}\right)$ calculation. Symbols and solid lines are experimental averaged mass spectral density $\Delta N / \Delta \log (m)$. Dashed lines are mass-based distribution function $\mathrm{d} n / \mathrm{d} \log (m)$ after application of an inversion procedure to the primary data.

function $\mathrm{d} n / \mathrm{d} m$ through the equation:

$$
\Delta N\left(m_{i}\right)=\sum_{z=1}^{\infty} \int_{0}^{\infty} \varepsilon(m) \Theta\left(z, m, m_{i}\right) f(z, m) \frac{\mathrm{d} n}{\mathrm{~d} m} \mathrm{~d} m,
$$

where $i$ is the number of the step in the CPMA scanning mode, $m_{i}$ and $\Theta$ are the mass setpoints and the respective transfer function, $f(z, m)$, is the fraction of particles of mass $m$ with $z$ elementary charges, $\varepsilon(m)$ is the transport efficiency through the system tubing. In most of our experiments, the particle distribution was rather narrow with a mass geometric standard deviation of about 1.10 , which is slightly more than the mass geometric standard deviation of the CPMA transfer function. Firstly, it provides a clear resolution of the peaks of multiple-charged particles (Symonds et al., 2011; McMurry et al., 2002). For particles passed through the DMA with mobility diameter setpoint $D_{\mathrm{b}}=70 \mathrm{~nm}$, the mass ratio of double to single charged particles registered by the CPMA is about 1.7 , which is considerably larger than the width of the particle distribution as well as the CPMA transfer function. Secondly, the variations in $\varepsilon(m)$ and $f(z, m)$ across the width of the distribution function are relatively small, which ensures a negligible shift in position of the maximums of $\Delta N / \Delta m$ and $\mathrm{d} n / \mathrm{d} m$, although their amplitude values and widths are different.

The Twomey-Markowski algorithm (Markowski, 1987; Alofs and Balakumar, 1982) was applied to invert Eq. (3) and estimate the mass-based distribution function, as described in detail in the supplemental information to Rawat et al. (2016). We used the expressions provided there for transport and 
detection efficiency, converted to the mass domain. For deconvolution we employed the idealized triangular transfer function recommended by the manufacturer and measured by Olfert et al. (2006). The results are shown in Fig. 2 (dashed curves). The deconvoluted functions are narrower than the experimental distributions, but the modal mass values of $\Delta N / \Delta m$ and $\mathrm{d} n / \mathrm{d} m$ agree within $2 \%$. This inversion procedure was applied to the CPMA measurements, although we consider this not to be critical in this study. Some exceptions are discussed below.

The precision of the CPMA particle mass measurements mainly depends on the uncertainties of voltage, rotation speed, airflow rate and the profile between the electrodes. The voltage and speed are software controlled inside the CPMA within $0.02 \%$ and registered in the data output files. Calculated from this data (using Eq. 1), the mass setpoint uncertainty was less than $0.1 \%$. The airflow rate seems the most unstable factor, which fluctuated within $2-3 \%$. The flow rate affects the CPMA resolution and not the mass setpoint, so its contribution to the mass uncertainty is difficult to account for. Practically, the mass uncertainty was determined as the standard deviation of repeated measurements, which took into account the DMA setpoint uncertainty as well. There were a lot of dry aerosol measurements distributed throughout the experimental period, and for dry aerosol the mass uncertainty was $5 \%$, which agrees with the results of other researches (McMurry et al., 2002; Johnson et al., 2015). Naturally, the number of repeated measurements at a other RHs is not as large, and although the measured masses usually were scattered within $5 \%$, we assumed the mass uncertainty in humid conditions to be equal to the transfer function width ( $8 \%$ ). According to Eq. (2b) this uncertainty translates into a $10 \%$ uncertainty in $G_{m}$.

\section{Results and discussion}

\subsection{Ammonium sulfate and sodium chloride mass growth}

Ammonium sulfate $\left(\left(\mathrm{NH}_{4}\right)_{2} \mathrm{SO}_{4}\right)$ and sodium chloride $(\mathrm{NaCl})$ were chosen as reference substances to calibrate the HCPMA set-up since their hygroscopic properties are well known from measurements (Gysel et al., 2002; Mikhailov et al., 2004, 2009; Kreidenweis et al., 2005; Biskos et al., 2006a, b; Sorooshian et al., 2008) and theory (Clegg et al., 1998a, b; Martin, 2000; Topping et al., 2005; Mikhailov et al., 2013; Cheng et al., 2015). Figure 3 shows the results obtained for $\left(\mathrm{NH}_{4}\right)_{2} \mathrm{SO}_{4}$ and $\mathrm{NaCl}$ particles with initial mobility diameter $D_{\mathrm{b}}=60 \mathrm{~nm}$ and dry masses of $0.18 \pm 0.01$ and $0.21 \pm 0.01 \mathrm{fg}$ respectively. It illustrates the typical behaviour of crystalline inorganic salt aerosol particles interacting with water vapour (Martin, 2000).

Upon hydration, the deliquescence transition results in a stepwise increase of the HCPMA-derived mass at
$\mathrm{RH}=80 \pm 2 \%$ for ammonium sulfate and at $\mathrm{RH}=75 \pm 2 \%$ for sodium chloride. The obtained deliquescence relative humidity (DRH) is in good agreement with literature data of DRH for crystalline $\left(\mathrm{NH}_{4}\right)_{2} \mathrm{SO}_{4}: 79.9 \pm 0.5 \%$ and for $\mathrm{NaCl}$ : $75.3 \pm 0.1 \%$ (Gysel et al., 2002; Seinfeld and Pandis, 2006; Mikhailov et al., 2009, and references therein). The measured mass growth factors are in agreement with the "full Köhler model" (Brechtel and Kreidenweis, 2000b; Rose et al., 2008; Mikhailov et al., 2009) based on the water activity parameterization derived from the Aerosol Inorganics Model (AIM, Clegg et al., 1998a). Averaged over the whole range of 40$95 \% \mathrm{RH}$, the mean relative deviations between measurement and model results were within $10 \%$. It should be noted that a $10 \%$ deviation in mass growth factor corresponds to $3 \%$ accuracy in size growth factor, which is typical for HTDMAderived data (Duplissy et al., 2009). For $\mathrm{NaCl}$ particles at $\mathrm{RH}$ above the DRH, the measured $G_{m}$ values are systematically below (by $\sim 5 \%$ ) those predicted in theory. Most likely, the observed discrepancy was caused by the short residence time in the humidifier system $(\sim 10 \mathrm{~s})$, so that the sodium chloride droplets had not yet reached their equilibrium masses (Cruz and Pandis, 2000; Chan and Chan, 2005; Duplissy et al., 2009). For both $\left(\left(\mathrm{NH}_{4}\right)_{2} \mathrm{SO}_{4}\right)$ and $\mathrm{NaCl}$ particles, intermediate growth factors between dry and deliquesced particles were observed (Fig. 3 - blue crosses). This looks like the apparently non-prompt phase transition that was previously described by Mikhailov et al. (2004) and Biskos et al. (2006a). The most reasonable explanation for the observed effect is due to RH variability inside the CPMA. The $2 \% \mathrm{RH}$ uncertainty is too high to accurately resolve the particles' deliquescence point. The RH appears to vary slightly while the aerosol particles pass through the CPMA. Thus, when measuring near the deliquescence point, the initially solid particles may deliquesce somewhere inside CPMA if the local $\mathrm{RH}$ exceeds the DRH. These inner deliquescence events lead to observation of transitional particle mass spectra (Fig. 4a), which seems to be an artefact of this technique.

In dehydration mode, both ammonium sulfate and sodium chloride particles reveal hygroscopic hysteresis, but efflorescence of salt solution droplets in the CPMA experiments occurred as a rule at much higher RH than the reference efflorescence relative humidity (ERH): $35 \pm 2 \%$ for $\left(\mathrm{NH}_{4}\right)_{2} \mathrm{SO}_{4}$ and $43 \pm 3 \%$ for $\mathrm{NaCl}$ (Seinfeld and Pandis, 2006). Approximately in half of the measurements, an abrupt decrease of solution droplet mass was observed at $\mathrm{RH}=65 \pm 5 \%$ for $\left(\mathrm{NH}_{4}\right)_{2} \mathrm{SO}_{4}$ and at $\mathrm{RH}=60 \pm 3 \%$ for $\mathrm{NaCl}$. In this case, the peaks of effloresced and non-effloresced particles were merged into a unimodal distribution with intermediate modal mass as illustrated in Fig. 4b. These mass distributions account for the transitional growth factor values observed during efflorescence (Fig. 3, red crosses). The application of the inversion procedure described in Sect. 2 to the experimental data reveals a multi-modal structure of the mass spectra (dashed lines, Fig. 4b). Although both deliquesced and effloresced transitional spectra are unimodal (Fig. 4a and b), 

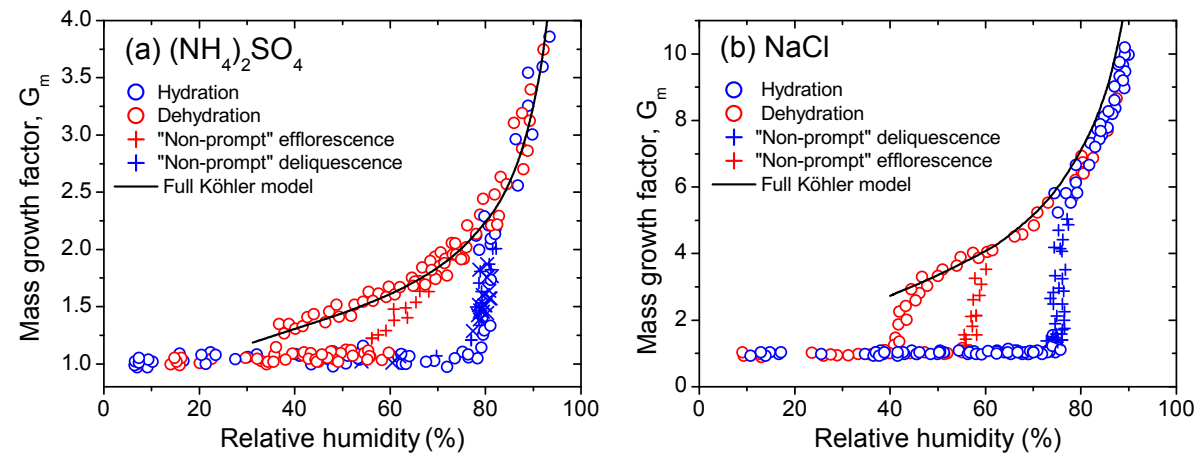

Figure 3. The mass growth factor $\left(G_{m}\right)$ of ammonium sulfate (a) and sodium chloride (b) aerosol particles observed as a function of relative humidity (RH) compared to the full Köhler model: blue and red crosses represent apparent non-prompt deliquescence and efflorescence thresholds.
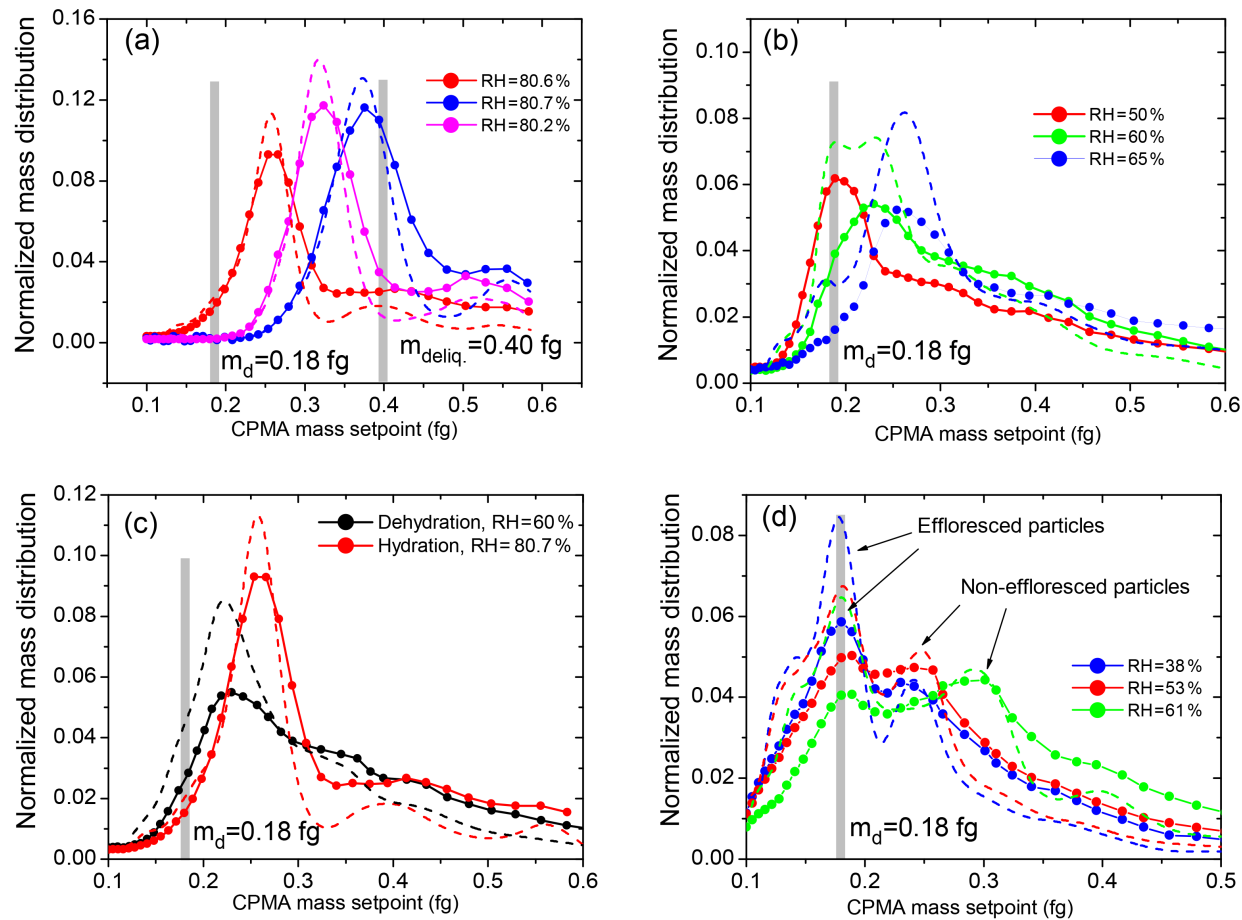

Figure 4. Normalized particle number mass distributions of ammonium sulfate particles with initial dry modal mass $m_{\mathrm{d}}=0.18 \mathrm{fg}$ measured at RH close to the deliquescence and efflorescence thresholds of (a) unimodal intermediate mass distributions observed near the DRH, $m_{\text {deliq. }}=0.40 \mathrm{fg}$ is the mass of fully deliquesced particles; (b) unimodal and (d) bimodal mass distributions observed for particle dehydration at $\mathrm{RH}<65 \%$; (c) mass distribution broadening for particle hydration (red), and dehydration (black). The RH uncertainty was estimated to be $\pm 1.5 \%$. Symbols and solid lines are normalized experimental averaged mass spectral density $\Delta N /(N \Delta \log (m))$. Dashed lines are massbased distribution function $\mathrm{d} n /(N \mathrm{~d} \log (m))$ after application of an inversion procedure to the primary data.

their mass distribution shape and width are different. The hydration transitional spectra are narrower than the dehydration ones (Fig. 4c), which is due to the irreversibility of the particles' efflorescence. As a result, the output aerosol in dehydration mode is a mixture of droplets and dry particles, while in hydration mode it consists mainly of droplets. It is important to note that as with the DMA, any change of the particle water uptake inside the CPMA leads to a deflection of the particle trajectory due to the disturbance of the force balance. Therefore, all the transient mass spectra should be considered unreliable.

The spatial variability of RH inside the CPMA induced by the above-mentioned frictional warming appears to be the most likely cause of the observed efflorescence at RH close to the DRH. It is reasonable to suppose that the relative humidity is minimally close to the electrode surface, and that 
at $\mathrm{RH}<\mathrm{DRH}$ salt crystals may form first on the electrode surface. The gap between the two cylinders is only $\sim 1 \mathrm{~mm}$, and due to force imbalance, some metastable droplets could make contact with crystals on the surface, triggering an efflorescence transition as specified in Fig. 5. Since the mass of these newly formed effloresced particles is smaller than that of the initial droplets, the electrostatic forces $\left(F_{\mathrm{e}}\right)$ will prevail over the centrifugal forces $\left(F_{\mathrm{c}}\right)$, and the dry particles will either move towards the inner electrode or pass through the gap as shown in Fig. 5. In the latter case, the CPC will count these particles as droplets with the preset mass, thus distorting the actual mass distribution (Fig. 4b). It should be noted that contact efflorescence inside the CPMA was suggested here as the most plausible explanation for the observed early ERH. Additional experimental and modelling studies are needed to test this hypothesis.

Contact efflorescence is especially effective if the seed crystal is of the same composition as the anticipated crystalline phase. In this case, due to the isochemical collision, no activation barrier is required for nucleation, and efflorescence will occur at ERH close DRH. Contact efflorescence experiments by Davis et al. (2015) have shown that upon collision of $\left(\left(\mathrm{NH}_{4}\right)_{2} \mathrm{SO}_{4}\right)_{\text {solid }}$ with $\left(\left(\mathrm{NH}_{4}\right)_{2} \mathrm{SO}_{4}\right)_{\text {droplet }}$ and $\mathrm{NaCl}_{\text {solid }}$ with $\mathrm{NaCl}_{\text {droplet }}$, the efflorescence of the metastable droplets occurred at $79 \pm 2 \% \mathrm{RH}$ for $\left(\mathrm{NH}_{4}\right)_{2} \mathrm{SO}_{4}$ and at $74 \pm 2 \% \mathrm{RH}$ for $\mathrm{NaCl}$. In contrast, heterochemical collision did not significantly influence ERH. For example, single contact of a metastable $\left(\mathrm{NH}_{4}\right)_{2} \mathrm{SO}_{4}$ droplet with dry $\mathrm{NaCl}$ particles induced $\left(\mathrm{NH}_{4}\right)_{2} \mathrm{SO}_{4}$ crystallization at $\mathrm{ERH}=38 \pm 2 \%$, that is only by $\sim 3 \% \mathrm{RH}$ higher than the homogeneous ERH $(\sim 35 \%)$.

In some cases, the particle mass distribution measured by the CPMA bifurcated into a bimodal one, indicating a partial efflorescence of solution droplets. This is exactly the situation in which application of the data inversion procedure makes the bimodal structure of distribution function more prominent. Figure $4 d$ shows the particle number mass distribution measured at relative humidities close to the efflorescence threshold upon dehydration of the $\left(\mathrm{NH}_{4}\right)_{2} \mathrm{SO}_{4}$ particles. The first distribution mode corresponds to the mass of the initial dry particles $\left(m_{\mathrm{d}}=0.18 \mathrm{fg}\right)$ and represents effloresced particles. The second mode represents non-effloresced droplets. Its position is shifted to larger particle masses and depends on RH. The ratio of the peak heights depends on $\mathrm{RH}$ as well; i.e. the lower the $\mathrm{RH}$, the more the effloresced particle mode becomes predominant compared to the noneffloresced one.

Since in this case effloresced and non-effloresced peaks are resolved (Fig. 4d), their measured masses were used to calculate the mass growth factor of the salt particles (Eq. 1). This makes it possible to follow the dehydration mode down to $\mathrm{RH}=42 \pm 2 \%$ for sodium chloride (Fig. 3a) and $\mathrm{RH}=37 \pm 2 \%$ for ammonium sulfate (Fig. $3 \mathrm{~b}$ ) particles. For $\mathrm{NaCl}$ particles the observed efflorescence relative humidity is in good agreement with the HTDMA-derived val-

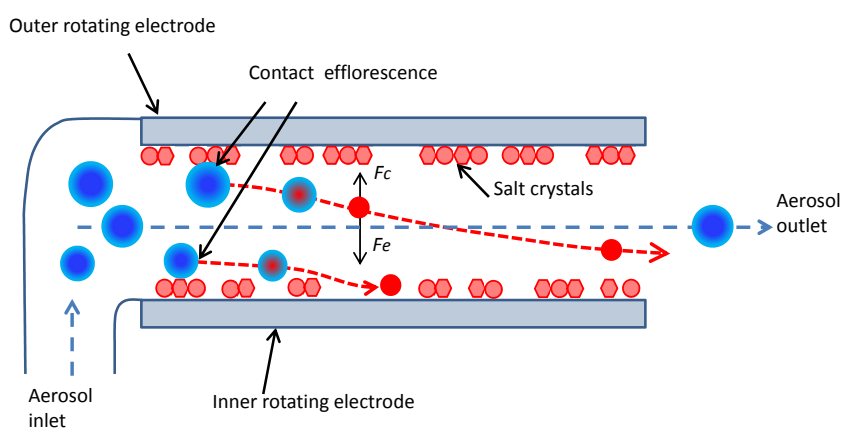

Figure 5. Schematic representation of the metastable microdroplets efflorescence when coming into contact with salt crystals deposited on the electrode surface. Explanation and designations are given in the text.

ues of ERH $=44 \pm 2.5 \%$ obtained by Biskos et al. (2006b) for $60 \mathrm{~nm}$ particles. For $\left(\mathrm{NH}_{4}\right)_{2} \mathrm{SO}_{4}$, the HCMPA-derived value is at the upper end of the literature ERH values reported for particles $\leq 100 \mathrm{~nm}$ ranging from 30 to $37 \% \mathrm{RH}$ (Biskos et al., 2006a; Badger et al., 2006; Sjorgen et al., 2007; Mikhailov et al., 2009).

\subsection{Ambient aerosol measurements}

The DMA-HCPMA set-up was used to determine the hygroscopic properties of ambient atmospheric aerosol particles. The sampling site $\left(59^{\circ} 88^{\prime} \mathrm{N}, 29^{\circ} 82^{\prime} \mathrm{E}\right)$ was located in a suburban forest environment at Petrodvoretz, about $35 \mathrm{~km}$ southwest of Saint Petersburg, Russia (SPB sample). The measurements were carried out in the daytime on 25 and 26 March 2014. The ambient aerosols were first dried by a silica gel diffusion dryer to a residual $\mathrm{RH}<10 \%$ and then entered into the DMA-HCMPA system. The measurement procedure was the same as used for single component solutes. During the sampling campaign, the particle mass distribution was relatively stable. A modal mobility diameter of $D_{\mathrm{b}}=160 \mathrm{~nm}$ was selected for the hygroscopic growth measurements, which corresponds to $m_{\mathrm{d}}=3.5 \mathrm{fg}$. The precision of the particle diameter measurements was generally about $\pm 10 \%$ and the total uncertainty of the mass growth factor was estimated to be $14 \%$. Concurrent chemical analysis of the aerosol fractions in the size range of $20-300 \mathrm{~nm}$ indicated that the SPB sample consisted mostly of inorganic ions, generally in the form of ammonium sulfate $\left(f_{\mathrm{AS}} \sim 0.45\right)$, and organics $\left(f_{\mathrm{OC}} \sim 0.52\right)$ (Mikhailov et al., 2017). Inserting these mass fraction values $\left(f_{i}\right)$ and densities of $\rho_{\mathrm{OC}}=1.4 \mathrm{~g} \mathrm{~cm}^{-3}$ (Kostenidou et al., 2007), $\rho_{\mathrm{AS}}=1.77 \mathrm{~g} \mathrm{~cm}^{-3}$ (Lide, 2005) in Eq. (4) yields an average weighted bulk density of $\rho_{\mathrm{d}}=1.6 \mathrm{~g} \mathrm{~cm}^{-3}$.

$\rho_{\mathrm{d}}=\left(\sum_{i} \frac{f_{i}}{\rho_{i}}\right)^{-1}$

Figure 6a shows the mass growth factors, determined as a function of relative humidity for hydration and dehydration. 

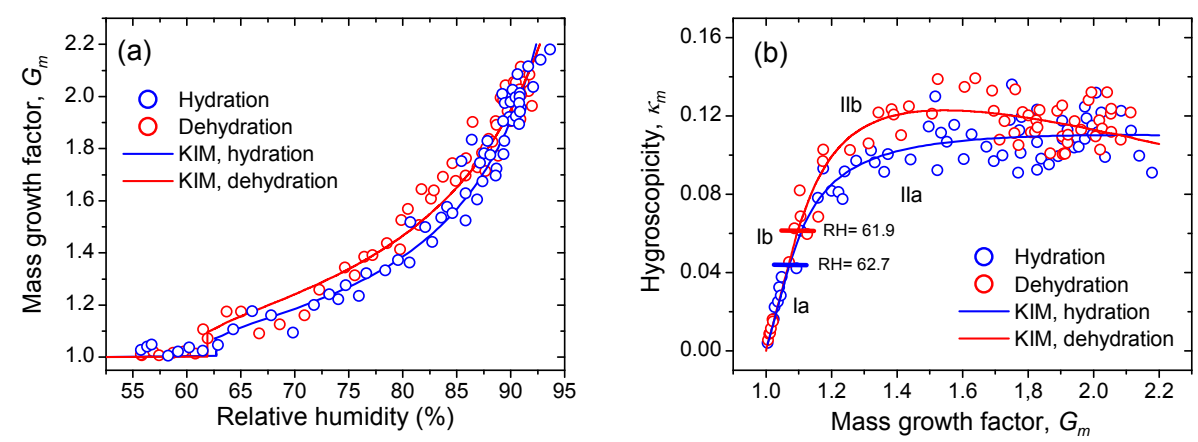

Figure 6. Hygroscopic properties of ambient atmospheric aerosols with preset $m_{\mathrm{d}}=3.5 \mathrm{fg}\left(D_{\mathrm{b}}=160 \mathrm{~nm}\right)$ : (a) mass growth factor $\left(G_{m}\right)$ observed as a function of relative humidity compared to KIM; (b) mass-based hygroscopicity parameter $\left(\kappa_{m}\right)$ calculated as a function of mass growth factor. The data points are from two repetitive experiments of hydration (blue circles) and dehydration (red circles). The lines are fits of KIM Eqs. (5) and (6). The labels I (Ia,Ib), II (IIa, IIb) indicate different regimes of hygroscopicity (Eqs. 5 and 6); the borders of the corresponding fit intervals are indicated by blue (hydration) and red (dehydration) bars (b).

The onset of deliquescence was noticeable at $\sim 63 \% \mathrm{RH}$ and then water uptake gradually increased, reaching a mass growth factor value of 2.2 at $\sim 93 \% \mathrm{RH}$. Upon dehydration, the mass growth factors were slightly larger than those observed for the hydration mode, and at $\sim 62 \%$ RH particles underwent efflorescence. Both deliquescence and efflorescence transitions were not pronounced. Most likely, the observed reversible stepwise particle mass change in the hydration and in the dehydration experiments was related to a phase transition between collapsed and swollen semi-solid organic structures (Mikhailov et al., 2009). In the framework of the $\kappa$-mass interaction model (KIM), this transition can be regarded as a quasi-eutonic threshold between metastable amorphous phases (Mikhailov et al., 2013).

Figure $6 \mathrm{~b}$ shows the mass-based hygroscopicity parameter $\left(\kappa_{m}\right)$ plotted against the mass growth factor. The concentration dependence of $\kappa_{m}$ was calculated as specified in Mikhailov et al. (2013). Briefly, in analogy with the volumebased hygroscopicity parameter (Petters and Kreidenweis, 2007), we define a mass-based hygroscopicity parameter, $\kappa_{m}$ :

$$
\frac{1}{a_{\mathrm{w}}}=1+\kappa_{m} \frac{m_{\mathrm{d}}}{m_{\mathrm{w}}}
$$

where $a_{\mathrm{w}}$ is the activity of water, $m_{\mathrm{d}}$ is the total mass of the dry particle material, and $m_{\mathrm{w}}$ is the mass of water in the wet particle (aqueous droplet). By combining Eqs. (1) and (5) we obtain

$a_{\mathrm{w}}=\left(\frac{\kappa_{m}}{G_{m}-1}+1\right)^{-1}$.

Based on Eq. (6) an approximate mass-based $\kappa_{m}$-Köhler equation can be written as follows (Mikhailov et al., 2013):

$$
\frac{\mathrm{RH}}{100 \%} \approx\left(\frac{\kappa_{m}}{G_{m}-1}+1\right)^{-1} \exp \left(\frac{4 \sigma_{\mathrm{w}} M_{\mathrm{w}}}{R T \rho_{\mathrm{w}}}\left[\frac{\pi \rho_{\mathrm{w}}}{6 G_{m} m_{\mathrm{d}}}\right]^{\frac{1}{3}}\right),
$$

where $M_{\mathrm{w}}, \sigma_{\mathrm{w}}$, and $\rho_{\mathrm{w}}$ are the molar mass, surface tension, and density of pure water, $R$ is the universal gas constant,
$T$ is the temperature. From the measurement of the $G_{m}(\mathrm{RH})$ data, we derived the $\kappa_{m}$ values (Fig. 6b) using Eqs. (6) and (7) at $m_{\mathrm{d}}=3.5 \mathrm{fg}$.

For mixed organic-inorganic particles, KIM describes three distinctly different regimes of hygroscopicity: (I) a quasi-eutonic deliquescence and efflorescence regime at lowhumidity, where substances are just partly dissolved and also exist in a non-dissolved phase; (II) a gradual deliquescence and efflorescence regime at intermediate humidity, where different solutes undergo gradual dissolution or solidification in the aqueous phase; and (III) a dilute regime at high humidity, where the solutes are fully dissolved approaching their dilute hygroscopicity. In each of these regimes, the concentration dependence of $\kappa_{m}$ can be described by simplified model equations.

Regime I:

$\kappa_{m}=k_{1}\left(G_{m}-1\right)$

Regime II:

$\kappa_{m}=k_{2}+k_{3}\left(G_{m}-1\right)+k_{4}\left(G_{m}-1\right)^{-1}+k_{5}\left(G_{m}-1\right)^{-2}$

Regime III:

$\kappa_{m}=k_{5}\left(G_{m}-1\right)^{-2}+k_{6}$.

Here, $k_{1}$ to $k_{6}$ are fit parameters related to the solubility and interaction coefficients of all involved chemical components (Mikhailov et al., 2013; Eqs. 39-44). In the dilution mode (III), $\kappa_{m}$ decreases with increasing $G_{m}$ and becomes concentration independent at very high values of $G_{m}$ (Eq. 6). According to Eq. (10), the fit parameter $k_{6}$ can be regarded as the dilute hygroscopicity parameter of the investigated sample of particulate matter $\left(\kappa_{m}^{0}\right)$. In this experiment, the dilution mode (III) was not clearly pronounced, generally because in the DMA-HCPMA set-up the upper RH value does not exceed $\sim 95 \%$. Therefore, only quasi-eutonic deliquescence (Ia)/efflorescence (Ib) and gradual deliquescence 
Table 1. KIM fit parameters for the SPB sample with dry particle mass of $3.5 \mathrm{fg}\left(D_{\mathrm{b}}=160 \mathrm{~nm}\right)$. The columns $n$ and $R^{2}$ give the number of data points and the coefficient of determination of the fit.

\begin{tabular}{|c|c|c|c|c|}
\hline Regime & $n$ & $R^{2}$ & $\begin{array}{r}\text { Fit } \\
\text { equation }\end{array}$ & $\begin{array}{l}\text { Best fit parameter } \\
\pm \text { standard error }\end{array}$ \\
\hline Quasi-eutonic deliquescence (Ia) & 11 & 0.89 & 6 & $k_{1}=0.61 \pm 0.04$ \\
\hline Gradual deliquescence (IIa) & 60 & 0.63 & 7 & $\begin{array}{l}k_{2}=0.33 \pm 0.01 \\
k_{3}=-0.007 \pm 0.001 \\
k_{4}=-0.009 \pm 0.0002 \\
k_{5}=2.35 \times 10^{-4} \pm 1.08 \times 10^{-4}\end{array}$ \\
\hline Gradual efflorescence (IIb) & 62 & 0.66 & 6 & $\begin{array}{l}k_{2}=0.18 \pm 0.02 \\
k_{3}=-0.049 \pm 0.017 \\
k_{4}=-0.017 \pm 0.005 \\
k_{5}=5.67 \times 10^{-4} \pm 3.42 \times 10^{-4}\end{array}$ \\
\hline Quasi-eutonic efflorescence (Ib) & 11 & 0.91 & 7 & $k_{1}=0.63 \pm 0.03$ \\
\hline
\end{tabular}

(IIa)/efflorescence (IIb) regimes have been considered by using KIM model Eqs. (8) and (9) to fit the data points (Fig. 6b, solid lines). The obtained best-fit parameters $k_{1}-k_{5}$ are listed in Table 1.

By inserting KIM-derived values of $\kappa_{m}$ and $G_{m}$ in Eq. (7), we obtained the $G_{m}(\mathrm{RH})$ dependences displayed in Fig. 6a (solid lines). It can be seen that the model curves are in good agreement with the measurement data. Note that, for the quasi-eutonic regime (I), the combination of Eqs. (6) and (8) yields a constant water activity value given by $a_{\mathrm{w}}=$ $\left(k_{1}+1\right)^{-1}$. This relation yields the following quasi-eutonic RH values characterizing the deliquescence (Ia) and efflorescence (Ib) phase transitions: 62.7 and $61.9 \%$ (Fig. 6a, b).

Under the volume-additivity assumption, the mass-based parameter, $\kappa_{m}$, can be converted to the Petters and Kreidenweis (2007) volume-based parameter, $\kappa_{v}$, by the relation:

$\kappa_{v}=\kappa_{m} \frac{\rho_{\mathrm{d}}}{\rho_{\mathrm{w}}}$

For the calculation of $\kappa_{v}$ we chose the $\kappa_{m}$ fit value of $0.11 \pm 0.04$, which is the intercept of the model curves at $G_{m}=2.1$ (Fig. 6b). This $\kappa_{m}$ value corresponds to the most dilute solution concentration in the particles achieved in the given experiment. Inserting $\kappa_{m}=0.11 \pm 0.04$ and the estimated density $\rho_{\mathrm{d}}=1.6 \mathrm{~g} \mathrm{~cm}^{-3}$ in Eq. (11) yields $\kappa_{v}=$ $0.18 \pm 0.08$. The obtained value is in reasonable agreement with the CCNC-derived $\kappa_{v}=0.22 \pm 0.12$ averaged from 21 to 31 March 2014 measured at the same site for $100 \mathrm{~nm}$ particles (Mikhailov et al., 2017) and $\kappa_{v} \sim 0.2$ reported by Zhang et al. (2014) and Rose at al. (2010) for freshly emitted aerosols from urban pollutants. Most likely, the low $\kappa_{v}$ value we obtained arises from mixed particles with coatings by hydrophobic organics, produced from fossil fuel combustion and biomass burning (Andreae and Rosenfeld, 2008).

\section{Conclusion}

A new DMA-HCPMA technique for measuring the hygroscopic properties of laboratory and ambient aerosols is introduced. Laboratory tests with inorganic compounds were conducted to verify the proposed technique in hydration and dehydration modes. Ammonium sulfate and sodium chloride particles were used as reference inorganic aerosols. A fairly good agreement was observed between measured mass growth factors and those calculated with a full Köhler model. The difference between experimental results and theoretically predicted liquid particle growth factor values does not exceed $10 \%$. The measured DRHs of ammonium sulfate and sodium chloride aerosols are in agreement with literature values within $2 \% \mathrm{RH}$ uncertainty. In the dehydration experiment, efflorescence occurred at higher RH than the ERH of homogenous nucleation. This effect appeared to be associated with contact efflorescence initiated by collision between metastable micro-droplets and salt crystals deposited on the electrode surface.

The DMA-HCPMA tandem system was also applied to measure mass growth factors of urban aerosol particles. The kappa mass interaction model (KIM) was used to characterize and parameterize non-ideal solution behaviour and concentration-dependent water uptake by atmospheric aerosol samples in the 50-95\% $\mathrm{RH}$ range. Overall, both test results and field measurements have shown that the DMAHCPMA system described above can be applied to aerosol size-resolved mass growth factor measurements in hydration and dehydration modes up to $95 \%$ RH.

Data availability. Data used in this study can be made available upon request to the author. 
Competing interests. The authors declare that they have no conflict of interest.

Acknowledgements. This work was supported by the Max Planck Society (MPG), RFBR grants 16-05-00718 and 16-0500717, and Saint Petersburg State University (SPBU) grant BRICS 11.37.220.2016. We thank the Geomodel Research Center at Saint Petersburg State University for help with chemical analysis of the ambient aerosol samples.

Edited by: F. Pope

Reviewed by: P. H. McMurry, M. Irwin, and one anonymous referee

\section{References}

Alofs, D. J. and Balakumar, P.: Inversion to obtain aerosol size distributions from measurements with a differential mobility analyzer, J. Aerosol Sci., 13, 513-527, doi:10.1016/00218502(82)90017-9, 1982.

Andreae, M. O. and Rosenfeld, D.: Aerosol-cloud-precipitation interactions. Part 1. The nature and sources of cloud-active aerosols, Earth-Sci. Rev., 89, 13-41, 2008.

Badger, C. L., George, I., Griffiths, P. T., Braban, C. F., Cox, R. A., and Abbatt, J. P. D.: Phase transitions and hygroscopic growth of aerosol particles containing humic acid and mixtures of humic acid and ammonium sulphate, Atmos. Chem. Phys., 6, 755-768, doi:10.5194/acp-6-755-2006, 2006.

Berg, O. H., Swietlicki, E., and Krejci, R.: Hygroscopic growth of aerosol particles in the marine boundary layer over the $\mathrm{Pa}$ cific and Southern oceans during the First Aerosol Characterization Experiment (ACE I), J. Geophys. Res., 103, 16535-16534, doi:10.1029/97JD02851, 1998.

Biskos, G., Paulsen, D., Russell, L. M., Buseck, P. R., and Martin, S. T.: Prompt deliquescence and efflorescence of aerosol nanoparticles, Atmos. Chem. Phys., 6, 4633-4642, doi:10.5194/acp-64633-2006, 2006a.

Biskos, G., Malinowski, A., Russell, L. M., Buseck, P. R., and Martin, S. T.: Nanosize effect on the deliquescence and the efflorescence of sodium chloride particles, Aerosol Sci. Tech., 40, 97106, $2006 b$.

Brand, P., Ruoss, K., and Gebhart, J.: Performance of a mobile aerosol spectrometer for an insitu characterization of environmental aerosols in Frankfurt city, Atmos. Environ. 26, 24512457, 1992.

Brechtel, F. J. and Kreidenweis, S. M.: Predicting particle critical supersaturation from hygroscopic growth measurements in the humidified TDMA. Part II: Laboratory and Ambient Studies, J. Atmos. Sci. 57, 1872-1887, 2000a.

Brechtel, F. J. and Kreidenweis, S. M.: Predicting particle critical supersaturation from hygroscopic growth measurements in the humidified TDMA. Part I: Theory and Sensitivity Studies, J. Atmos. Sci. 57, 1854-1871, 2000b.

Chan, M. N. and Chan, C. K.: Mass transfer effects in hygroscopic measurements of aerosol particles, Atmos. Chem. Phys., 5, 2703-2712, doi:10.5194/acp-5-2703-2005, 2005.
Cheng, Y., Su, H., Koop, T., Mikhailov, E., and Pöschl, U.: Size dependence of phase transitions in aerosol nanoparticles, Nat. Commun., 6, 5923, doi:10.1038/ncomms6923, 2015.

Cheng, Y. F., Wiedensohler, A., Eichler, H., Heintzenberg, J., Tesche, M., Ansmann, A., Wendisch, M., Su, H., Althausen, D., Herrmann, H., Gnauk, T., Bruggemann, E., Hu, M., and Zhang, Y. H.: Relative humidity dependence of aerosol optical properties and direct radiative forcing in the surface boundary layer at Xinken in Pearl River Delta of China: An observation based numerical study, Atmos. Environ., 42, 6373-6397, doi:10.1016/j.atmosenv.2008.04.009, 2008.

Clegg, S. L., Brimblecombe, P., and Wexler, A. S.: A thermodynamic model of the system $\mathrm{H}^{+}-\mathrm{NH}_{4}^{+}-\mathrm{Na}^{+}-\mathrm{SO}_{4}^{2-}-\mathrm{NO}_{3}-\mathrm{Cl}^{-}-$ $\mathrm{H}_{2} \mathrm{O}$ at $298.15 \mathrm{~K}$, J. Phys. Chem. A, 102, 2155-2171, 1998a.

Clegg, S. L., Brimblecombe, P., and Wexler, A. S.: A thermodynamic model of the system $\mathrm{H}^{+}-\mathrm{NH}_{4}^{+}-\mathrm{SO}_{4}^{2-}-\mathrm{NO}_{3}--\mathrm{H}_{2} \mathrm{O}$ at tropospheric temperatures, J. Phys. Chem. A, 102, 2137-2154, 1998b.

Covert, D. S., Heintzenberg, J., and Hansson, H.-C.: Electro-Optical Detection of External Mixtures in Aerosols, Aerosol Sci. Tech., 12, 446-456, 1990.

Cruz, C. N. and Pandis, S. N.: Deliquescence and hygroscopic growth of mixed inorganic-organic atmospheric aerosol, Environ. Sci. Technol., 34, 4313-4319, 2000.

Davis, R. D., Lance, S., Gordon, J. A., Ushijima, S. B., and Tolbert, M.A.: Contact efflorescence as a pathway for crystallization of atmospherically relevant particles, P. Natl. Acad. Sci. USA, 112, 15815-15820, 2015.

DeCarlo, P. F., Slowik, J. G., Worsnop, D. R., Davidovits, P., and Jimenez, J. L.: Particle morphology and density characterization by combined mobility and aerodynamic diameter measurements. Part 1: Theory, Aerosol Sci. Tech., 38, 1185-1205, 2004.

Duplissy, J., Gysel, M., Sjogren, S., Meyer, N., Good, N., Kammermann, L., Michaud, V., Weigel, R., Martins dos Santos, S., Gruening, C., Villani, P., Laj, P., Sellegri, K., Metzger, A., McFiggans, G. B., Wehrle, G., Richter, R., Dommen, J., Ristovski, Z., Baltensperger, U., and Weingartner, E.: Intercomparison study of six HTDMAs: results and recommendations, Atmos. Meas. Tech., 2, 363-378, doi:10.5194/amt-2-363-2009, 2009.

Ehara, K., Hagwood, C., and Coakley, K. J.: Novel method to classify aerosol particles according to their mass-to-charge ratio: aerosol particle mass analyser, J. Aerosol Sci. 27, 217-234, 1996.

Eichler, H., Cheng, Y. F., Birmili, W., Nowak, A., Wiedensohler, A., Brüggemann, E., Gnauk, T., Herrmann, H., Althausen, D., Ansmann, A., Engelmann, R., Tesche, M., Wendisch, M., Zhang, Y. H., Hu, M., Liu, S., and Zeng, L. M.: Hygroscopic properties and extinction of aerosol particles at ambient relative humidity in South-Eastern China, Atmos. Environ., 42, 6321-6334, doi:10.1016/j.atmosenv.2008.05.007, 2008.

Fierz-Schmidhauser, R., Zieger, P., Wehrle, G., Jefferson, A., Ogren, J. A., Baltensperger, U., and Weingartner, E.: Measurement of relative humidity dependent light scattering of aerosols, Atmos. Meas. Tech., 3, 39-50, doi:10.5194/amt-3-392010, 2010a.

Fierz-Schmidhauser, R., Zieger, P., Gysel, M., Kammermann, L., DeCarlo, P. F., Baltensperger, U., and Weingartner, E.: Measured and predicted aerosol light scattering enhancement factors at the high alpine site Jungfraujoch, Atmos. Chem. Phys., 10, 23192333, doi:10.5194/acp-10-2319-2010, 2010b. 
Geller, M., Biswas, S., and Sioutas, C.: Determination of Particle Effective Density in Urban Environments with a Differential Mobility Analyzer and Aerosol Particle Mass Analyzer, Aerosol Sci. Tech., 40, 709-723, 2006.

Gysel, M., Weingartner, E., and Baltensperger, U.: Hygroscopicity of aerosol particles at low temperatures. 2. Theoretical and experimental hygroscopic properties of laboratory generated aerosol, Environ. Sci. Technol., 36, 63-68, 2002.

Gysel, M., Weingartner, E., Nyeki, S., Paulsen, D., Baltensperger, U., Galambos, I., and Kiss, G.: Hygroscopic properties of watersoluble matter and humic-like organics in atmospheric fine aerosol, Atmos. Chem. Phys., 4, 35-50, doi:10.5194/acp-4-352004, 2004.

Hänel, G.: The properties of atmospheric aerosol particles as function of relative humidity at the thermodynamic equilibrium with surrounding moist air, Adv. Geophys. 19, 73-188, 1976.

Haywood, J. and Boucher, O.: Estimates of the direct and indirect radiative forcing due to tropo-spheric aerosols: A review, Rev. Geophys., 38, 513-543, 2000.

Hegg, D. A., Covert, D. S., Jonsson, H., and Covert, P. A.: An instrument for measuring size-resolved aerosol hygroscopicity at both sub- and super-micron sizes, Aerosol Sci. Tech., 41, 873883, doi:10.1080/02786820701506955, 2007.

Hering, S. V. and McMurry, P. H.: Optical counter response to monodisperse atmospheric aerosols, Atmos. Environ. 25, 463468, 1991

Johnson, T. J., Olfert, J. S., Yurteri, C. U., Cabot, R., and McAughey, J.: Hygroscopic effects on the mobility and mass of cigarette smoke particles, J. Aerosol Sci., 86, 69-78, 2015.

Kim, J., Yoon, S. C., Jefferson, A., and Kim, S. W.: Aerosol hygroscopic properties during Asian dust, pollution, and biomass burning episodes at Gosan, Korea in April 2001, Atmos. Environ. 40, 1550-1560, 2006.

Kondo, Y., Komazaki, Y., Miyazaki, Y., Moteki, N., Takegawa, N., Kodama, D., Deguchi, S., Nogami, M., Fukuda, M., Miyakawa, T., Morino, Y., Koike, M., Sakurai, H., and Ehara, K.: Temporal variations of elemental carbon in Tokyo, J. Geophys. Res. 111, D12205, doi:10.1029/2005JD006257, 2006.

Kostenidou, E., Pathak, R. K., and Pandis, S. N.: An algorithm for the calculation of secondary organic aerosol density combining AMS and SMPS data, Aerosol Sci. Tech., 41, 1002-1010, 2007.

Kreidenweis, S. M., Koehler, K., DeMott, P. J., Prenni, A. J., Carrico, C., and Ervens, B.: Water activity and activation diameters from hygroscopicity data - Part I: Theory and application to inorganic salts, Atmos. Chem. Phys., 5, 1357-1370, doi:10.5194/acp-5-1357-2005, 2005.

Kreisberg, N. M., Stolzenburg, M. R., Hering, S. V., Dick, W. D., and McMurry, P. H.: A new method for measuring the dependence of particle size distributions on relative humidity, with application to the Southeastern aerosol and visibility study, J. Geophys. Res., 106, 14935-14949, 2001.

Lee, C. and Hsu, W.: A novel method to measure aerosol water mass, J. Aerosol Sci. 29, 827-837, 1998.

Lide, D. R.: CRC Handbook of Chemistry and Physics, 86th ed., CRC Press, Boca Raton, FL, USA, 2005.

Magi, B. I. and Hobbs. P. V.: Effects of humidity on aerosols in southern Africa during the biomass burning season, J. Geophys. Res., 108, 8495, doi:10.1029/2002JD002144, 2003.
Markowski, G. R.: Improving Twomey's algorithm for inversion of aerosol measurement data, Aerosol Sci. Tech., 7, 127-141, doi:10.1080/02786828708959153, 1987.

Martin, S. T.: Phase transitions of aqueous atmospheric particles, Chem. Rev., 100, 3403-3453, 2000.

Massling, A., Leinert, S., Wiedensohler, A., and Covert, D.: Hygroscopic growth of sub-micrometer and one-micrometer aerosol particles measured during ACE-Asia, Atmos. Chem. Phys., 7, 3249-3259, doi:10.5194/acp-7-3249-2007, 2007.

McMurry, P. H. and Stolzenburg, M. R.: On the sensitivity of particle-size to relative-humidity for Los Angeles aerosols, Atmos. Environ., 23, 497-507, 1989.

McMurry, P. H., Wang, X., Park, K., and Ehara, K.: The relationship between mass and mobility for atmospheric particles: a new technique for measuring particle density, Aerosol Sci. Tech., 36, 227-238, 2002.

Mikhailov, E., Vlasenko, S., Niessner, R., and Pöschl, U.: Interaction of aerosol particles composed of protein and saltswith water vapor: hygroscopic growth and microstructural rearrangement, Atmos. Chem. Phys., 4, 323-350, doi:10.5194/acp-4-323-2004, 2004.

Mikhailov, E., Vlasenko, S., Martin, S. T., Koop, T., and Pöschl, U.: Amorphous and crystalline aerosol particles interacting with water vapor: conceptual framework and experimental evidence for restructuring, phase transitions and kinetic limitations, Atmos. Chem. Phys., 9, 9491-9522, doi:10.5194/acp-9-9491-2009, 2009.

Mikhailov, E., Vlasenko, S., Rose, D., and Pöschl, U.: Mass-based hygroscopicity parameter interaction model and measurement of atmospheric aerosol water uptake, Atmos. Chem. Phys., 13, 717740, doi:10.5194/acp-13-717-2013, 2013.

Mikhailov, E. F., Merkulov, V. V., Vlasenko, S. S., Ryshkevich, T. I., and Pöschl U. J.: Filter-based differential hygroscopicity analyzer of aerosol particles, Izv. Atmos. Ocean. Phy.+, 47, 747759, 2011.

Mikhailov, E. F., Ivanova, O. A., Vlasenko, S. S., Nebosko, E. Yu., and Ryshkevich, T. I.: Cloud condensation nuclei activity of the Aitken mode particles near St. Petersburg, Russia, Izv. Atmos. Ocean. Phy.+, in review, 2017.

Olfert, J. S. and Collings, N.: New method for particle mass classification - the Couette centrifugal particle mass analyzer, J. Aerosol Sci., 36, 1338-1352, 2005

Olfert, J. S., Reavell, K. St. J., Rushton, M. G., and Collings, N.: The experimental transfer function of the Couette centrifugal particle mass analyzer, J. Aerosol Sci., 37, 1840-1852, 2006.

Orr Jr., C., Hurd, F. K., and Corbett, W. J.: Aerosol size and relative humidity, J. Colloid Sci., 13, 472-482, 1958.

Pagels, J., Khalizov, A. F., McMurry, P. H., and Zhang, R. Y.: Processing of soot by controlled sulphuric acid and water condensation - mass and mobility relationship, Aerosol Sci. Tech., 43, 629-640, 2009.

Peng, C. G. and Chan, C. K.: The water cycles of water-soluble organic salts of atmospheric importance, Atmos. Environ., 35, 1183-1192, 2001.

Petters, M. D. and Kreidenweis, S. M.: A single parameter representation of hygroscopic growth and cloud condensation nucleus activity, Atmos. Chem. Phys., 7, 1961-1971, doi:10.5194/acp-71961-2007, 2007. 
Rader, D. J. and McMurry, P. H.: Application of the tandem differential mobility analyzer to studies of droplet growth or evaporation, J. Aerosol Sci. 17, 771-787, 1986.

Rastak, N., Silvergren, S., Zieger, P., Wideqvist, U., Ström, J., Svenningsson, B., Maturilli, M., Tesche, M., Ekman, A. M. L., Tunved, P., and Riipinen, I.: Seasonal variation of aerosol water uptake and its impact on the direct radiative effect at Ny-Ålesund, Svalbard, Atmos. Chem. Phys., 14, 7445-7460, doi:10.5194/acp14-7445-2014, 2014.

Rawat, V. K., Buckley, D. T., Kimoto, S., Lee, M.-H., Fukushima, N., and Hogan Jr., C. J.: Two-dimensional size-mass distribution function inversion from differential mobility analyzer-aerosol particle mass analyzer (DMA-APM) measurements, J. Aerosol Sci. 92, 70-82, 2016.

Rose, D., Gunthe, S. S., Mikhailov, E., Frank, G. P., Dusek, U., Andreae, M. O., and Pöschl, U.: Calibration and measurement uncertainties of a continuous-flow cloud condensation nuclei counter (DMT-CCNC): CCN activation of ammonium sulfate and sodium chloride aerosol particles in theory and experiment, Atmos. Chem. Phys., 8, 1153-1179, doi:10.5194/acp-8-11532008, 2008.

Rose, D., Nowak, A., Achtert, P., Wiedensohler, A., Hu, M., Shao, M., Zhang, Y., Andreae, M. O., and Pöschl, U.: Cloud condensation nuclei in polluted air and biomass burning smoke near the mega-city Guangzhou, China - Part 1: Size-resolved measurements and implications for the modeling of aerosol particle hygroscopicity and CCN activity, Atmos. Chem. Phys., 10, 33653383, doi:10.5194/acp-10-3365-2010, 2010.

Seinfeld, J. H. and Pandis, S. N.: Atmospheric chemistry and physics, J. Wiley \& Sons, New York, USA, 2006.

Shiraiwa, M., Zuend, A., Bertram, A. K., and Seinfeld, J. H.: Gasparticle partitioning of atmospheric aerosols: interplay of physical state, non-ideal mixing and morphology, Phys. Chem. Chem. Phys., 15, 11441-11453, doi:10.1039/C3CP90084C, 2013.

Sjogren, S., Gysel, M., Weingartner, E., Baltensperger, U., Cubison, M. J., Coe, H., Zardini, A. A., Marcolli, C., Krieger, U. R., and Peter, T.: Hygroscopic growth and water uptake kinetics of twophase aerosol particles consisting of ammonium sulphate, adipic and humic acid mixtures, J. Aerosol Sci., 38, 157-171, 2007.

Slowik, J. G., Cross, E. S., Han, J. H., Kolucki, J., Davidovits, P., Williams, L. R., Onasch, T. B., Jayne, J. T., Kolb, C. E., and Worsnop, D. R.: Measurements of morphology changes of fractal soot particles using coating and denuding experiments: implications for optical absorption and atmospheric lifetime, Aerosol Sci. Tech., 41, 734-750, 2007.

Snider, J. R. and Petters, M. D.: Optical particle counter measurement of marine aerosol hygroscopic growth, Atmos. Chem. Phys., 8, 1949-1962, doi:10.5194/acp-8-1949-2008, 2008.

Sorooshian, A., Hersey, S., Brechtel, F. J., Corless, A., Flagan, R. C., and Seinfeld, J. H.: Rapid, size-resolved aerosol hygroscopic growth measurements: differential aerosol sizing and hygroscopicity spectrometer Probe (DASH-SP), Aerosol Sci. Tech., 42, 445-464, 2008.
Stolzenburg, M. R. and McMurry, P. H.: Equations Governing Single and Tandem DMA Configurations and a New Lognormal Approximation to the Transfer Function, Aerosol Sci. Tech., 42, 421-432, 2008.

Swietlicki, E., Hansson, H.-C., Hämeri, K., Svenningsson, B., Massling, A., McFiggans, G., McMurry, P. H., Petäjä, T., Tunved, P., Gysel, M., Topping, D., Weingartner, E., Baltensperger, U., Rissler, J., Wiedensohler, A., and Kulmala M.: Hygroscopic properties of submicrometer atmospheric aerosol particles measured with H-TDMA instruments in various environments - a review, Tellus, 60B, 432-469, 2008.

Symonds, J. P. R., Rushton, M. G. Reavell, K. St. J., and Lowndes, C.: Behaviour of non- and multiply- charged aerosols in the centrifugal particle mass analyzer, American association for aerosol research conference, 3-7 October 2011, Orlando, USA, available at: http://www.cambustion.com/sites/ default/files/downloads/papers/2011/AAAR-2011-356.pdf (last access: 27 March 2017), 2011.

Tang, I. N. and Munkelwitz, H. R.: Composition and temperaturedependence of the deliquescence properties of hygroscopic aerosols, Atmos. Environ. 27, 467-473, 1993.

Tang, I. N. and Munkelwitz, H. R.: Water activities, densities, and refractive-indexes of aqueous sulfates and sodium-nitrate droplets of atmospheric importance, J. Geophys. Res., 99, 18801-18808, 1994.

Topping, D. O., McFiggans, G. B., and Coe, H.: A curved multicomponent aerosol hygroscopicity model framework: Part 1 - Inorganic compounds, Atmos. Chem. Phys., 5, 1205-1222, doi:10.5194/acp-5-1205-2005, 2005.

Twomey, S.: Atmospheric aerosols, Elsevier, New York, USA, 320 pp., 1977.

Vlasenko, S. S. and Mikhailov, E. F.: Tandem of differential mobility analyzer and centrifugal particle mass analyzer: application to hygroscopic growth of aerosol particles, European Aerosol Conference (EAC), 1-6 September 2013, Prague, Czech Republic, 2013.

Waggoner, A. P., Weiss, A. P., Ahlquist, N. C., Covert, D. S., and Charlson, R. J.: Optical characteristics of atmospheric aerosols, Atmos. Environ., 15, 1891-1909, 1981.

Zhang, F., Li, Y., Li, Z., Sun, L., Li, R., Zhao, C., Wang, P., Sun, Y., Liu, X., Li, J., Li, P., Ren, G., and Fan, T.: Aerosol hygroscopicity and cloud condensation nuclei activity during the $\mathrm{AC}^{3}$ Exp campaign: implications for cloud condensation nuclei parameterization, Atmos. Chem. Phys., 14, 13423-13437, doi:10.5194/acp14-13423-2014, 2014.

Zieger, P., Fierz-Schmidhauser, R., Weingartner, E., and Baltensperger, U.: Effects of relative humidity on aerosol light scattering: results from different European sites, Atmos. Chem. Phys., 13, 10609-10631, doi:10.5194/acp-13-10609-2013, 2013. 